\title{
Return on Investment of Free Colorectal Cancer Screening Tests in a Primarily Rural Uninsured or Underinsured Population in Northeast Texas
}

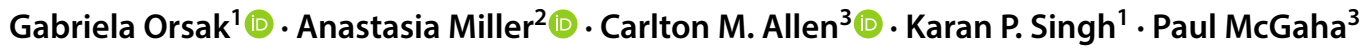

Published online: 23 May 2019

(c) The Author(s) 2019

\begin{abstract}
Background Colorectal cancer (CRC) is the third most common cancer in the USA. Its economic impact is extensive, and preventive screening services are warranted to help prevent it.

Objective We sought to examine the return on investment, in terms of reduced costs attributed to cancer prevention, of a CRC screening outreach program providing education and screening in a primarily rural region targeting the uninsured and underinsured.

Methods The expenditures of the Northeast Texas CRC screening program were calculated for the years of 2016 and 2017. Prices (\$US) were adjusted for inflation and converted to year 2017 values. The costs saved were calculated using the estimated costs of CRC care present in the literature.

Results For fiscal years 2016 and 2017, the program provided an average return of \$US1.46-2.06 for every tax dollar spent. Estimated cost avoidance was \$US165,080 per avoided case and estimated cost avoidance of \$US245,601 among early-stage cancer cases detected, resulting in potential savings ranging from $\$ \mathrm{US3}, 893,676$ to $\$ \mathrm{US} 4,837,923$.

Conclusion A CRC outreach program providing education and screening operating in less densely populated regions yields a positive return on investment.
\end{abstract}

\section{Key Points for Decision Makers}

Funding preventive screening programs for colorectal cancer is a long-term cost-saving strategy.

Even in rural areas with uninsured patients, educational and screening programs can be cost effective.

Gabriela Orsak

gabriela.orsak@uthct.edu

1 Department of Epidemiology and Biostatistics, School of Rural and Community Health, The University of Texas Health Science Center at Tyler, 11937 US HWY 271, Tyler, TX 75708-3154, USA

2 Department of Healthcare Policy, Economics and Management, The University of Texas Health Science Center at Tyler, Tyler, TX, USA

3 Department of Community Health, The University of Texas Health Science Center at Tyler, Tyler, TX, USA

\section{Background}

Colorectal cancer (CRC) is the third most common cancer among men and women in the USA [1]. Its economic impact is extensive, totaling \$US7.49 billion in 2000, and is estimated to increase to \$US 14.03 billion by 2020 in the USA [2]. However, the number of patients diagnosed and/ or succumbing to CRC and its subsequent economic burden can be lessened through the use of colonoscopy and/ or fecal immunochemical testing (FIT). Colonoscopy and FIT testing provide clinicians the opportunity to detect and subsequently remove precancerous polyps, thus preventing CRC [3]. Specifically, the majority of cases of CRC develop from adenomatous polyps, with a small percentage developing from hyperplastic polyps [4]. Currently, colonoscopy is considered the gold standard for CRC screening, as colonoscopies are the only CRC screening test that prevents CRC and evaluates the entire large bowel [5]. However, many individuals opt not to undergo coloscopies because of several factors, such as cost, distance, need for proper bowel preparation and fear/avoidance. Specifically, 
many patients have a fear of and avoid the procedure [6-8]. The procedure also requires proper bowel preparation to be effective. Finally, many (especially in rural areas such as Northeast Texas) have to travel long distances for specialty care (i.e., seeing a gastroenterologist to undergo a colonoscopy) and require help from a family member to drive them home after the procedure. This is especially true for the uninsured or underinsured, who do not get a choice on where free services may be provided. Alternatively, a stool test, such as the FIT, provides a less invasive and inexpensive alternative to colonoscopies. Individuals who elect FIT can collect a sample in the convenience of their own home, without the need for bowel preparation, and mail the sample to be examined. If the sample is returned as abnormal, individuals can then proceed to colonoscopy. FIT testing is a more cost-effective method for public health programs to provide more widespread testing for those who are underinsured or uninsured [9].

A large proportion of the population is left unscreened and at risk for CRC [10]. Although the Patient Protection and Affordable Care Act improved access to screening colonoscopies, an estimated 28.1 million Americans are uninsured [11]. Northeast Texas is a primarily rural, medically underserved region of Texas approximately the size of West Virginia. The region is largely unhealthy, with poor health outcomes for the five leading causes of death (heart disease, cancer, stroke, chronic respiratory diseases, and unintentional injury) and with many health disparities, including a substantial uninsured population and high smoking and adult obesity rates [12-14].

While the age-adjusted incidence of CRC for the state of Texas (38.1 per 100,000) [15] is similar to the national rate $(38.27$ per 100,000$)$ [16], the CRC incidence is higher in the primarily rural region of Northeast Texas (43.3 per 100,000) [15]. This follows a similar trend of CRC mortality, where rates in Northeast Texas (15.8-16.9 per $100,000)$ [17] exceed the state $(14.4$ per 100,000$)$ [17] and national (14.1 per 100,000) [18] averages. The reason behind these incidence rates may be multifaceted. For example, Northeast Texas reports one of the highest smoking rates in the state and has the highest obesity rate in the state [12-14]. In addition, non-adherence to cancer screening recommendations, diagnosis of cancer at a later stage, and higher cancer mortality is more likely among rural residents [19-21]. Another barrier to care includes distance. Residents often have to travel long distances to seek care, and the number of specialists in the area is often limited. This problem intensifies for older adults (who are the target population for CRC screening) or for those who are uninsured, especially since public transportation is lacking. Therefore, seeking CRC preventive services may not be a priority for individuals in these communities.
Currently, the Healthy People 2020 initiative set by the US Department of Health and Human Services aims to achieve a 70.5\% CRC screening rate [22]. However, even with the availability of multiple screening methods, CRC screening rates remain suboptimal in the general public, (62.4\%) [10] and in rural communities (58.2\%) [22], with rates being even lower in Northeast Texas (44.63\%) [23] and among the uninsured (25.1\%) [23]. The high CRC prevalence yet low screening rates in the Northeast Texas region are a growing concern.

Cancer can cause a significant financial burden on those who have insurance, with an even greater burden placed on the uninsured [24]. Patients with cancer are 2.5 times more likely to file for bankruptcy than those without cancer. Patients with CRC who file for bankruptcy have a 2.5 times higher mortality rate than those who do not file for bankruptcy [25]. Socioeconomic status also impacts medical treatment decisions, with lower-income patients with cancer focusing on avoiding costly treatment as opposed to higherincome patients with cancer, who focus on survival [26]. Colonoscopies are also independently associated with fewer deaths from CRC [27].

Therefore, the current CRC project aimed to provide screening services to the underinsured and uninsured in the form of free colonoscopies and/or FIT testing in a 19-county region in Northeast Texas. Furthermore, we aimed to assess the economic impact of this program. Specifically, we hypothesized that the program would yield a positive return on investment (ROI) from a programmatic perspective.

\section{Methods}

\subsection{Community Outreach Program}

The program was funded by the Cancer Prevention and Research Institute of Texas (CPRIT). Screening was conducted in a 19-county catchment area during the fiscal years (September 1-August 31) of 2016 and 2017. In total, 3002 individuals were screened through this program. Table 1 displays the medical and demographic variables of participants. The catchment area was primarily rural, with the exception of some small metropolitan statistical areas. Study participants were recruited either by referrals from clinics or through community outreach events targeting underinsured and uninsured individuals. The program was an education and screening program. Potential participants were educated on the importance of CRC screening, different methods of CRC screening, and the current program providing these screening services free of charge. Study participants seen at clinics deemed eligible were recommended/referred for colonoscopy and/or FIT test based on their preference and/ or provider recommendation. Screenings were provided free 
Table 1 Medical and demographic variables of participants $(n=3002)$

\begin{tabular}{ll}
\hline Variable & \\
\hline Sex & \\
Female & $2047(68.2)$ \\
Male & $955(31.8)$ \\
Race/ethnicity & \\
African American & $482(16.1)$ \\
Asian & $23(0.8)$ \\
Hispanic & $1058(35.2)$ \\
Non-Hispanic White & $1434(47.8)$ \\
Unknown/prefer not to say & $5(0.2)$ \\
Age, years & $56.96 \pm 5.1$ \\
Previous screening for CRC & \\
Yes & $611(20.4)$ \\
No & $1994(66.4)$ \\
Missing/unknown & $397(13.2)$ \\
Family history of CRC & \\
Yes & $219(7.3)$ \\
No & $2363(78.7)$ \\
Missing/unknown & $420(14.0)$ \\
\hline
\end{tabular}

Data are presented as $\mathrm{n}(\%)$ or mean \pm standard deviation unless otherwise indicated

$C R C$ colorectal cancer

of charge. An additional \$US20 gift card for transportation was provided upon completion of a colonoscopy. Participants who elected to take the FIT test were scheduled for colonoscopy if they had an abnormal FIT result (and subsequently received the same \$US20 gift card for transportation upon completion of colonoscopy). The team consisted of a Program Director, Co-Program Director, Program Manager, an Outreach Education Coordinator, Program Specialist, Nurse Navigator, and three Health Education Coordinators. The Program Manager, Outreach Education Coordinator, Program Specialist, Nurse Navigator, and Health Education Coordinators had completed the Texas Community Health Worker (CHW) certification training and maintained their certification by completing CHW continuing education requirements. They were also trained in motivational interviewing.

Recruitment had both a community-based and a clinical focus. Our strategy involved reaching out to individuals to make them aware of the need to undergo CRC screening, educating them about their screening options, performing the screening methodology of choice (FIT or colonoscopy), providing access to treatment for CRC, and providing follow-up. Individuals were recruited from clinics at The University of Texas Health Science Center at Tyler, health fairs, charity clinics, local health departments and districts, and federally qualified health centers. The primarily rural 19-county region known as Northeast Texas has an area of about 14,762 square miles [28] with a total population of 2,167,769 [29] in 2017. Eligibility for colonoscopy/FIT was determined after education outreach and/or physician recommendation.

To determine eligibility, US Preventive Services Task Force guidelines, which recommend screening all races/ ethnicities between the ages of 50 and 75 years [30], were followed. Individuals were eligible to participate if they were aged 50-75 years, spoke English or Spanish, were uninsured or underinsured, did not have a medical exclusion for the procedure(s) (e.g., taking blood thinners), and had not been previously diagnosed with CRC. Individuals also could not have had a colonoscopy in the last 10 years, a sigmoidoscopy in the last 5 years, or a stool test in the last year before becoming eligible for the CPRIT screening program. A breakdown of the budget can be seen in Table 2 .

\subsection{Return on Investment}

To calculate the ROI, several transformations and assumptions were utilized. All dollars were converted into quarter 3 , year 2017 values, as this was the end of fiscal year 2 . Converting all dollar values spent to a single month allowed meaningful discussion of expenditures across time. The original and converted budgets are provided in Table 3. The CMS Medicare Economic Index [31, 32] for quarter 3 of 2016 and 2017 were assumed for the budgets of year 1 and year 2, respectively, as they were the midpoints of

Table 2 Budgetary breakdown of the CPRIT screening program (\$US)

\begin{tabular}{lcc}
\hline Category & Year 2 budgeted & Year 3 budgeted \\
\hline Personnel & $209,069.20$ & $209,069.20$ \\
Fringe & $53,739.38$ & $53,739.38$ \\
Travel & 5000.00 & 5800.00 \\
Supplies & 3272.00 & 3272.00 \\
Contractual & $43,200.00$ & $51,200.00$ \\
Other & $449,017.00$ & $449,017.00$ \\
Total & $763,297.58$ & $772,097.58$ \\
\hline
\end{tabular}

CPRIT Cancer Prevention and Research Institute of Texas

Table 3 Inflationary adjustment of yearly budgets (\$US)

\begin{tabular}{lcc}
\hline & Nominal budget & $\begin{array}{l}\text { Inflation- } \\
\text { adjusted } \\
\text { budget }\end{array}$ \\
\hline Year 1 & 763,297 & 791,692 \\
Year 2 & 772,097 & 786,844 \\
Total & $1,535,394$ & $1,578,536$ \\
\hline
\end{tabular}


those fiscal years. As with other ROIs on cancer-screening programs, only direct costs related to the program were included [33]. Costs for polyp removal were included in ROI calculations.

During the course of this program, 433 people had adenomas (precancerous polyps) removed, and 12 people had suspected malignancies removed, although one turned out to be an adenoma. No records were kept of how many polyps were removed from each patient, so we conservatively assumed only one polyp per patient. Although this is unlikely given that the mean number of polyps per colonoscopy patient is $>1$ [34], we decided to err on the side of a conservative economic analysis. A review of the literature showed that approximately $5 \%$ of CRC adenomas become cancerous [35]. Accordingly, we assumed that $5 \%(n=22)$ of these individuals would have eventually developed malignant polyps, rounding to the closest whole-person number; meaning that we assumed a total of 22 people avoided requiring treatment for CRC. We also added the cost savings of the documented malignancies, as they constitute costs avoided. These 7 of 11 individuals who had cancer removed had early-stage CRC and therefore avoided the costs incurred for a stage IV CRC treatment, estimated in other literature to be \$US361,197 in year 2010 values [36] (\$US410,681 in 2017 values).

\subsection{Sensitivity Analysis}

A sensitivity analysis was conducted (Table 4) to factor in uncertainty in the analysis. It assumed different years to cancer development as well as different discount rates. The standard medical discount rate recommended by the Second Panel on Cost-Effectiveness in Health and Medicine was utilized as it is the standard medical discount rate in the literature [37]. An alternative discount rate of 5\% was used for comparison [38]. For patients who avoided cancer altogether, the estimated cost saving was \$US165,080 utilized [39]. During analysis, we used a conservative assumption that it would take 10 years to develop CRC, because this is an estimate for people with no polyps in their colonoscopies [40]. Other literature indicates that CRC can occur as early as 5 years after a colonoscopy [41].

Table 4 Costs avoided for 22 patients who had polyps removed (\$US)

\begin{tabular}{lll}
\hline & $3 \%$ discount rate & 5\% discount rate \\
\hline $\begin{array}{l}\text { 10 years to develop- } \\
\text { ment of cancer after } \\
\text { colonoscopy }\end{array}$ & $2,678,147$ & $2,174,469$ \\
$\begin{array}{l}5 \text { years to development } \\
\text { of cancer after colo- } \\
\text { noscopy }\end{array}$ & $3,118,716$ & $2,810,187$ \\
\hline
\end{tabular}

The seven patients who avoided late-stage CRC were included in the analysis as costs avoided. We assumed that these seven individuals avoided the difference between the late stage (\$US410,681) and average CRC treatment costs ( $\$$ US165,080), which is $\$$ US245,601. This amounts to a cost avoidance of $\$ \mathrm{US1} 1,719,207$ with these patients.

\section{Results}

Utilizing the estimated cost of CRC cancer care provided by the Milliman Research Report [39], we assumed that the avoided cost of CRC treatment was \$US165,080 per avoided case for the 22 patients who avoided cancer. Factoring in the range of cancerous cases that were likely to have developed, along with those who avoided late-stage cancer, the potential savings, in year 2017 values, ranged from \$US3,893,676 (assuming 10 years to development of cancer and a 5\% discount rate) to $\$ \mathrm{US} 4,837,923$ (assuming 5 years to development of cancer and a 3\% discount rate). With an equation of (cost saved - investment/investment $=$ ROI), the range for the ROI was $146 \%$ (\$US1.46) to $206 \%$ (\$US2.06) return in savings per tax dollar spent.

\section{Discussion}

The present study sought to examine the ROI of a CRC outreach program in a primarily rural population in Northeast Texas with high incidence of CRC and CRC mortality. As hypothesized, the program yielded a positive ROI despite additional costs not typical for other programs conducted in urban settings. These include costs accrued by the outreach program to reach rural residents living long distances from the screening site and having a smaller pool of potentially eligible individuals for screening due to regional rurality. For fiscal years 2016 and 2017, the program provided an average return of \$US1.46-2.06 for every dollar invested in the program. Estimated cost saved was $\$$ US 165,080 per avoided case and estimated potential savings ranged from $\$$ US3,893,676 to $\$$ US4,837,923.

Past research has focused on the cost effectiveness of CRC screenings [42-44]. However, the literature examining the economic impact of a CRC outreach program targeting the underinsured and uninsured in rural settings while utilizing colonoscopy and/or FIT testing is limited. The current study found that such a program could yield a positive ROI. This indicates that providing free CRC screening programs to the uninsured and underinsured is an efficient allocation of resources for state governments. As proposed in the literature, targeting CRC screening in rural areas could further help close the urban-rural health disparity gap [45]. 
The program had several advantages, including screening patients who would have normally not been screened due to lack of insurance or those who were underinsured, and therefore saving taxpayer dollars via saved future Medicaid/ Medicare expenditures or indigent care costs to the region. Other advantages included the utilization of FIT testing, a more cost-effective method for public health programs, enabling wider test dissemination for those who are underinsured and uninsured.

While technology for stool tests such as the FIT continue to improve in terms of detecting cancer, other technological advances can continue to shape the way CRC screening services are provided. Examples of technical change could include "virtual colonoscopies," a method in which an individual swallows a camera and a doctor uses that to examine the colon, may become more popular. Future studies assessing CRC screening programs may also evaluate methods such as these [46]. Another approach may be the use of toilets to detect disease [47]. While this technology seems promising for conditions such as diabetes, additional research is warranted for CRC [47].

The current study had several limitations. First, because there were no records of how many polyps were removed from each patient, we conservatively assumed only one polyp per patient. Although this is unlikely, given that the mean number of polyps per colonoscopy patient is $>1$ [34], we decided to err on the side of a conservative economic analysis. Each polyp has a chance for developing into cancer. It is entirely possible for a single patient to account for more than one avoided case of cancer, given that each polyp has a statistical chance of turning into a malignancy. This suggests that the ROI would have yielded a higher number if this information had been collected. Therefore, our calculations regarding the avoided cancer cases are potentially underestimated. The authors also did not have information regarding the size or type of the polyps, which further helps predict the likelihood of cancerous growth. This would have helped refine the amount saved by detecting the growth at a given state.

\section{Conclusions}

In the current study, we address the real-world ROI of a CRC outreach program in a primarily rural setting, demonstrating the practicality and fiscal savings of such a program among the underinsured and uninsured. This finding is an important consideration for public health programs and to consider instituting such programs in less densely populated areas as our program demonstrated a positive ROI in such an environment. In densely populated urban areas, people participating in outreach programs do not have to travel such long distances for screening. Such factors contribute to higher costs and reduce the ratio of ROIs in screening programs in rural regions.
However, providing such a program in rural areas is warranted, as rates of CRC in the Northeast Texas region are high and the program yielded a considerable positive programmatic ROI. In conclusion, a CRC outreach program of this design is a cost-effective option to reach the underinsured and uninsured.

Acknowledgements The authors would like to express their sincere gratitude to Edward Caldwell, Monica Collier, Miguel Gaona-Bustos, Sarah Malone, and Martha Ross for their help in data collection and management, community engagement, and support to make this project a success.

Author Contributions CMA, GO, and PM contributed to the acquisition of data and the conduct of the project. AM and KPS contributed to the statistical analysis of the project. All authors contributed to the generation of the initial draft of the article.

\section{Compliance with Ethical Standards}

Conflicts of interest GO, AM, CMA, KPS, and PM have no conflicts of interest that are directly relevant to the content of this article.

Data availability The datasets used and/or analyzed during the current study are available from the corresponding author on reasonable request.

Funding The current study was funded by the Cancer Prevention Research Institute of Texas (CPRIT). The content and the views expressed in this article are those of the author and do not necessarily reflect that of CPRIT. The funders had no role in study design, data collection and analyses, decision to publish, or preparation of the manuscript.

Open Access This article is distributed under the terms of the Creative Commons Attribution-NonCommercial 4.0 International License (http://creativecommons.org/licenses/by-nc/4.0/), which permits any noncommercial use, distribution, and reproduction in any medium, provided you give appropriate credit to the original author(s) and the source, provide a link to the Creative Commons license, and indicate if changes were made.

\section{References}

1. Centers for Disease Control and Prevention. Colorectal Cancer Statistics 2018 [updated 06/12/18. Available from: https://www. cdc.gov/cancer/colorectal/statistics/index.htm.

2. Yabroff KR, Mariotto AB, Feuer E, Brown ML. Projections of the costs associated with colorectal cancer care in the United States, 2000-2020. Health Econ. 2008;17(8):947-59.

3. American Cancer Society. Can colorectal polyps and cancer be found early? 2018 [updated 03/02/17. Available from: https:// www.cancer.org/cancer/colon-rectal-cancer/detection-diagnosisstaging/detection.html.

4. American Cancer Society. Colorectal cancer risk factors 2017 [Available from: https://www.cancer.org/cancer/colon-recta l-cancer/causes-risks-prevention/risk-factors.html.

5. Anderson JC, Fortinsky RH, Kleppinger A, Merz-Beyus AB, Huntington CG, Lagarde S. Predictors of compliance with free endoscopic colorectal cancer screening in uninsured adults. J Gen Intern Med. 2011;26(8):875-80. 
6. McLachlan S-A, Clements A, Austoker J. Patients' experiences and reported barriers to colonoscopy in the screening contexta systematic review of the literature. Patient Educ Couns. 2012;86(2):137-46.

7. Yang C, Sriranjan V, Abou-Setta AM, Poluha W, Walker JR, Singh $\mathrm{H}$. Anxiety associated with colonoscopy and flexible sigmoidoscopy: a systematic review. The American journal of gastroenterology. 2018:1.

8. Kerrison RS, von Wagner C, Green T, Winfield M, Macleod U, Hughes M, et al. Rapid review of factors associated with flexible sigmoidoscopy screening use. Preventive medicine. 2018.

9. Imperiale TF, Ransohoff DF, Itzkowitz SH, Levin TR, Lavin P, Lidgard GP, et al. Multitarget stool DNA testing for colorectal-cancer screening. N Engl J Med. 2014;370(14):1287-97.

10. U.S. Department of Health and Human Services. C-16 Increase the proportion of adults who receive a colorectal cancer screening based on the most recent guidelines 2018 [updated 02/27/18. Available from: https://www.healthypeople.gov/2020/data-search/Search-theData\#objid $=4054$; topic-area $=3513$;

11. Barnett JC, Berchick ER. Health Insurance Coverage in the United States: 2016. Washington, DC; 2017.

12. The Health Status of Northeast Texas 2016 [press release]. Austin, TX: UT Health Northeast/University of Texas System Office of Population Health2016.

13. Texas Department of State Health Services. Obesity data 2016 [Available from: https://www.dshs.texas.gov/Obesity/Data/.

14. Texas Department of State Health Services. The burden report: cardiovascular disease and stroke in Texas. TX: Austin; 2008.

15. Texas Cancer Registry. Age-adjusted invasive cancer incidence rates in Texas colon \& Rectum, 2011-2015 by public health region 2018 [Available from: https://www.cancer-rates.info/tx/.

16. National Cancer Institute. Browse the SEER Cancer Statistics Review 1975-2014 2017 [Available from: https://seer.cance r.gov/csr/1975_2014/browse_csr.php?sectionSEL=6\&pageS EL=sect_06_table.06.html.

17. Texas Cancer Registry. Age-adjusted cancer mortality rates in Texas Colon \& Rectum, 2011-2015 by public health region 2018 [Available from: https://www.cancer-rates.info/tx/.

18. National Cancer Institute. SEER cancer statistic review (CSR) 197420142017 [Available from: https://seer.cancer.gov/csr/1975_2014/ browse_csr.php?sectionSEL=6\&pageSEL=sect_06_table.09.html.

19. Cole AM, Jackson JE, Doescher M. Urban-rural disparities in colorectal cancer screening: cross-sectional analysis of 1998-2005 data from the Centers for Disease Control's Behavioral Risk Factor Surveillance Study. Cancer Med. 2012;1(3):350-6.

20. Fan L, Mohile S, Zhang N, Fiscella K, Noyes K. Self-reported cancer screening among elderly medicare beneficiaries: a Rural-Urban Comparison. J Rural Health. 2012;28(3):312-9.

21. Hines R, Markossian T, Johnson A, Dong F, Bayakly R. Geographic residency status and census tract socioeconomic status as determinants of colorectal cancer outcomes. Am J Public Health. 2014;104(3):e63-71.

22. U.S. Department of Health and Human Services. Healthy People 2020 Washington DC: U.S. Department of Health and Human Services, Office of Disease Prevention and Health Promotion; [updated 02/26/18. Available from: https://www.healthypeople.gov/2020/ topics-objectives/topic/cancer/objectives.

23. Hall J. Colorectal cancer sceening data. In: Orsak G, editor. 2018.

24. Yabroff KR, Lund J, Kepka D, Mariotto A. Economic burden of cancer in the United States: estimates, projections, and future research. Cancer Epidemiol Biomarkers Prev. 2011;20(10):2006-14.

25. Ramsey SD, Bansal A, Fedorenko CR, Blough DK, Overstreet KA, Shankaran V, et al. Financial insolvency as a risk factor for early mortality among patients with cancer. J Clin Oncol. 2016;34(9):980.

26. Wong Y-N, Egleston BL, Sachdeva K, Eghan N, Pirollo M, Stump TK, et al. Cancer patients' trade-offs among efficacy, toxicity and out-of-pocket cost in the curative and non-curative setting. Medical Care. 2013;51:9.

27. Baxter NN, Goldwasser MA, Paszat LF, Saskin R, Urbach DR, Rabeneck L. Association of colonoscopy and death from colorectal cancer. Ann Intern Med. 2009;150(1):1-8.

28. National Association of Counties. Texas 2017 [Available from: https://web.archive.org/web/20070213225518/http://www.naco. org/Template.cfm?Section=Find_a_County\&Template $=\% 2$ Fcff iles $\% 2$ Fcounties $\% 2$ Fstate.cfm\&state.cfm\&statecode $=$ tx.

29. United States Census Bureau. American Fact Finder 2017 [Available from: https://factfinder.census.gov/faces/tableservices/jsf/pages /productview.xhtml? src $=$ bkmk

30. U.S. Preventive Services Task Force. Colorectal Cancer: Screening 2016 [Available from: https://www.uspreventiveservicestaskforce. org/Page/Document/UpdateSummaryFinal/colorectal-cancer-scree ning2?ds $=1 \& \mathrm{~s}=$ colon.

31. Centers for Medicare \& Medicaid Services. Market Basket Data 2018 [Available from: https://www.cms.gov/Research-Statistics -Data-and-Systems/Statistics-Trends-and-Reports/MedicareProgram RatesStats/MarketBasketData.html.

32. Bureau of Labor Statistics. n.d. [Available from: https://data.bls.gov/ timeseries/CUUR0000SA0.

33. Skrundevskiy AN, Omar OS, Kim J, Soliman AS, Korolchuk TA, Wilson FA. Return on investment analysis of breast cancer screening and downstaging in Egypt: implications for developing countries. Value Health Regional Issues. 2018;16:22-7.

34. Kahi CJ, Anderson JC, Waxman I, Kessler WR, Imperiale TF, Li X, et al. High-definition chromocolonoscopy vs high-definition white light colonoscopy for average-risk colorectal cancer screening. Ame J Gastroenterol. 2010;105(6):1301 .

35. Bujanda L, Cosme A, Gil I, Arenas-Mirave JI. Malignant colorectal polyps. World J Gastroenterol. 2010;16(25):3103.

36. Chastek B, Kulakodlu M, Valluri S, Seal B. CN4 total health care costs for colorectal cancer patients following metastatic diagnosis. Value Health. 2012;15(4):A1.

37. Sanders GD, Neumann PJ, Basu A, Brock DW, Feeny D, Krahn M, et al. Recommendations for Conduct, Methodological Practices, and Reporting of Cost-effectiveness Analyses: second Panel on CostEffectiveness in Health and MedicineRecommendations From the Second Panel on Cost-Effectiveness in Health and MedicineRecommendations From the Second Panel on Cost-Effectiveness in Health and Medicine. JAMA. 2016;316(10):1093-103.

38. Drummond MF, Sculpher MJ, Claxton K, Stoddart GL, Torrance GW. Methods for the economic evaluation of health care programmes. 4th ed. Oxford: Oxford University; 2015.

39. Dieguez G, Ferro C, Pyenson BS. A multi-year look at the cost burden of cancer care. 2017.

40. Singh H, Turner D, Xue L, Targownik LE, Bernstein CN. Risk of developing colorectal cancer following a negative colonoscopy examination evidence for a 10 -year interval between colonoscopies. JAMA. 2006;295(20):2366-73.

41. Samadder NJ, Curtin K, Tuohy TM, Pappas L, Boucher K, Provenzale D, et al. Characteristics of missed or interval colorectal cancer and patient survival: a population-based study. Gastroenterology. 2014;146(4):950-60.

42. American Cancer Society. The Cost of Cancer 2017 [Available from: https://www.acscan.org/policy-resources/costs-cancer.

43. Pignone M, Saha S, Hoerger T, Mandelblatt J. Cost-effectiveness analyses of colorectal cancer screening: a systematic review for the US Preventive Services Task Force. Ann Intern Med. 2002;137(2):96-104.

44. Schreuders EH, Ruco A, Rabeneck L, Schoen RE, Sung JJ, Young GP, et al. Colorectal cancer screening: a global overview of existing programmes. Gut. 2015;64(10):1637-49.

45. Bergin RJ, Emery J, Bollard RC, Falborg AZ, Jensen H, Weller D, et al. Rural-Urban Disparities in Time to Diagnosis and Treatment 
for Colorectal and Breast Cancer. Cancer Epidemiol Biomark Prev. 2018;27(9):1036-46.

46. Patel JD, Chang KJ. The role of virtual colonoscopy in colorectal screening. Clin Imaging. 2016;40(2):315-20.
47. Shankland S. AI toilets will scan your poop to diagnose your ailments. cnet. 2018 11/12/18. 